\title{
Evaluation of Disaster Management E-Learning Webs in Turkey
}

Kubilay KAPTAN, Istanbul Aydin Univ., Disaster Education, App. and Res. Cen., kubilaykaptan@aydin.edu.tr

Onur YILMAZ, Istanbul Aydin Univ., Disaster Education, App. and Res. Cen., onuryilmaz@aydin.edu.tr

\begin{abstract}
It is emphasized that Turkey experiences frequent earthquakes, causing extensive losses to economy, life and limb. In order to mitigate the losses due earthquakes, a number of issues are identified to be studied and managed properly on a national scale. Firstly, the importance of education and research about earthquakes and earthquake preparedness, from cradle to grave, is stressed. Secondly, for a successful solution of the risk mitigation problems, the legislative and financial structures as well as the social and technical organizations are presented.

Recommendations are given, concerning the disasters management, dealing with emergency matters during and after the earthquake, and also the risk management, dealing with preparations before the earthquake. Finally, the problems related to inventory of buildings, repair and retrofitting issues, earthquake insurance, supervision of design and construction of buildings are discussed.

E-learning is a new project for education based on the adoption of new computerised, multimedia and telematic technologies. Its application has deeply changed the concept of a teacher-based teaching to a student-centred educational project. It offers a great flexibility in the educational methodology, in the administration of contents, in the synchronous and/or asynchronous interaction between teachers and students, in the organisation and in the structure of the course, in the educational plans, in the support, the tracking and the evaluation of the student. E-learning could represent a great resource and a possible revolution in the concept of education and in the field of disaster education as well.

In Turkey, there are some important websites concerning disaster education. These websites are reviewed to evaluate if these sites provide good e-learning environments. The official websites concerning disaster education in Turkey are scorched and the websites are reviewed according to the established protocol. Each website has been evaluated by two independent reviewers. The average scores were obtained by averaging the two scores. Of the available 6 websites, the total scores of these 6 websites varied from 42 points to 28 points (average $34+12$ points). In conclusion, this report demonstrated that the e-learning of disaster education was still primitive in Turkey. It should be the first priority to implement a well-established elearning environment to provide good disaster education.

Keywords : e-learning, e-learning in disaster education, web based education
\end{abstract}




\section{Introduction}

Turkey, by virtue of its geographic location, experiences one damaging earthquake almost every year. In fact, the number of earthquakes occurred in Turkey, within the last century, with magnitudes greater than $M=5$, is 122 . Thus, the period of occurrence is virtually ten months, for a damaging earthquake in Turkey. This is the highest rate of occurrence in the world, in any country.

Over a period of one hundred years, a total of 98000 people died, and about 550000 buildings are heavily damaged, during the earthquakes in Turkey. Financially speaking, the direct losses to the economy of these earthquakes, on the average, have been approximately 500 million US dollars per year.

Unfortunately, the amount of research conducted in Turkey, in order to prevent these losses is not adequate. Perhaps, if only 5 per cent of these losses were spent for research in earthquake engineering, these losses would have been significantly reduced.

During the August 17, 1999 Kocaeli earthquake of $\mathrm{M}_{\mathrm{w}}=7.4$ and also during the November 12, 1999 Bolu-Düzce earthquake of $\mathrm{M}_{\mathrm{w}}=7.2$, a total of 17500 people died, 45000 people wounded. Out of 854000 residential units, 108400 residential units either collapsed or damaged severely beyond repair, 105000 suffered moderate damages and 117000 suffered minor damages. There has been a great awareness in the public opinion towards the earthquakes and earthquake preparedness.

In fact, immediately after these two earthquakes, the Law No.4708, governing the rules and regulations for the supervision of building design and construction in Turkey, is enacted on June 29, 2001 by the Turkish Parliament, also a National Earthquake Council is established under the auspices of the Turkish Scientific and Technical Research Agency (TUBITAK), for the purpose of preparing national strategies in mitigation of earthquake hazard; and further all Provincial Governments and local municipal bodies organized very modern and sophisticated Disaster Coordination Centers, throughout the Country. There are however, yet a lot of things to do in this regard.

\section{Education and Research}

In every country, the earthquakes and protective measures against earthquakes, also the ways and means of mitigation of earthquake hazards, should be studied at all levels of formal education, from elementary schools to Universities. It is also essential that necessary awareness education in earthquakes should be also given to children at pre-school age, and also to adults at post-school era. Administrators of schools, hospitals, private and public institutions also require courses, seminars and educational programs for the purpose of awareness of problems related to earthquakes and their hazards.

Since, only the civil engineers and architects are responsible for the proper and safe design of buildings, the aseismic design principles should be an integral and compulsory part of their undergraduate curricula. Unfortunately, in the Turkish universities, these Courses, if at all 
available, are technical electives. The engineers and architects already in practice, should be given on the job training, in order to refresh their knowledge, as well as to furnish them with new technological ideas, rules, methods and standards. The professional associations in Turkey have been already engaged in these educational activities on regular basis. Earthquake engineering research is also important. The volume of experimental as well as theoretical research in earthquake engineering at universities should be increased by obtaining additional financial support from the private and public institutions.

The areas of earthquake related research are very versatile, encompassing a variety of fields, such as civil engineering, structural engineering, earthquake engineering, geotechnical engineering, geological and geophysical engineering, city planning, architecture, social sciences (economy, administration, civil defence, insurance, financing, etc). Pre-earthquake activities of research and any spending of resources for the mitigation of hazards, virtually reduce in multifolds the possible losses to economy during the earthquakes.

\section{Methods}

\section{Study websites}

We searched the official websites concerning disaster education in Turkey are searched and reviewed the websites are reviewed according to the established protocol. Each website has been evaluated by two independent reviewers. The average scores were obtained by averaging the two scores. If the difference of any score concerning a specific category was more than 5 points, the third reviewer was invited to re-evaluate and re-score. The average would be the result of the two closest values.

1. Official website of Istanbul Technical University, www.aym.itu.edu.tr

2. Official website of Istanbul Aydin University, www.aydin.edu.tr

3. Official website of Bogazici University, www.koeri.boun.edu.tr

4. Official website of Izzet Baysal University, www.imidb.ibu.edu.tr

5. Official website of Disaster and Emergency Management Presidency of Turkey, www.afad.gov.tr

6. Official website of Istanbul Metropolitan Municipality, www.ibb.gov.tr

\section{Review protocol}

E-learning should provide rapid correction and addition of teaching content; explorative learning; ubiquitous access, time and place independency; individual adaptation to foreknowledge of students; enrichment of traditional teaching modes by multimedia-based preparation of contents; and improved interaction possibilities compared to traditional distance learning media. It is explored that if the disaster education-related e-learning 
websites in Turkey can provide such requirements. These categories are evaluated by three independent experts who gave the scores for each of the following categories (from 1 to 5).

Table1. Scores for web sites

\begin{tabular}{|c|l|c|c|c|c|c|c|}
\hline \multirow{2}{*}{} & \multicolumn{2}{|c|}{ Categories } & \multicolumn{5}{c|}{ Scores (from 1 to 5) } \\
\cline { 3 - 8 } & & Site 1 & Site 2 & Site 3 & Site 4 & Site 5 & $\begin{array}{c}\text { Site } \\
\mathbf{6}\end{array}$ \\
\hline $\mathbf{1}$ & Rapid updating of teaching content and material & 5 & 4 & 5 & 5 & 4 & 4 \\
\hline $\mathbf{2}$ & Explorative learning & 4 & 4 & 5 & 4 & 5 & 5 \\
\hline $\mathbf{3}$ & Independent time, place and access & 5 & 5 & 5 & 5 & 5 & 5 \\
\hline $\mathbf{4}$ & Individual adaptation & 5 & 5 & 5 & 5 & 5 & 5 \\
\hline $\mathbf{5}$ & Multimedia-based preparation & 1 & 4 & 4 & 3 & 2 & 4 \\
\hline $\mathbf{6}$ & Interaction possibilities & 1 & 1 & 1 & 1 & 1 & 1 \\
\hline $\mathbf{7}$ & Continued education tests & 1 & 1 & 3 & 1 & 1 & 1 \\
\hline $\mathbf{8}$ & Certification & 5 & 5 & 5 & 5 & 5 & 5 \\
\hline $\mathbf{9}$ & Post-test evaluation and grading & 3 & 3 & 3 & 3 & 1 & 1 \\
\hline $\mathbf{1 0}$ & Multi-language approach & 5 & 5 & 5 & 5 & 5 & 5 \\
\hline
\end{tabular}

\section{Statistical analysis}

Demographic data were analyzed by $t$ test and chi-square test where appropriate. The comparative

results were presented as point estimate and interval estimate (eg, the difference of the proportions, means, and 95\% confidence interval [CI] for difference). The ê statistic was used for calculating the degree of agreement in selecting high-risk ED discharged between the reviewers. All data were abstracted from records and keyed into and analyzed in Excel 2013(Microsoft Co., Redmond, WA, USA). A $P$ value less than 0.05 was considered as statistically significant.

\section{Results}

As mentioned in the section of method, we reviewed the available 6 websites by items in detail. Six websites were reviewed and discussed by three independent reviewers. As to rapid updating of teaching content and material, three of the websites (50\%) were updated per week ( 5 points), and three (50\%) were updated per two weeks ( 4 points). Three of the websites (50\%) had good explorative learning (5 points), whereas the other 3 websites $(50 \%)$ had average explorative learning (4 points). All of the websites $(100 \%)$ had independent time, place and access ( 5 points) and individual adaptation (5 points). As to multimediabased preparation, there were primary availabilities in 2 websites (33\%; 4 points). There were no primary interaction possibilities in all websites (100\%; 1 point), There was only one website $(1 / 6,17 \%)$ that has weak continued education tests (3 points), whereas the other 5 websites did not have such services ( 1 point). All of the websites $(100 \%)$ had certification (5 
point). 4 of the websites have weak post-test evaluation and grading services ( $66 \%, 3$ points). 2 of the websites (\%34, did not have this service (1 point). All of the websites $(100 \%)$ had multi-language approach (including English and Turkish) (5 points).

\section{Discussion}

This study demonstrated that there was still no satisfactory e-learning environment concerning disaster education in Turkey. Because of its popularity and generalization, disaster education should be incorporated into friendly e-learning websites immediately to provide good information and concepts to the public. In addition, the rating of the websites depends not only on the experts' opinions, but also on the rating from the students. The data is limited in that fact that it lacked student attitude in understanding of basic concepts and utilizing these learning sources. In general, the acceptance of a course was largely due to its congruence with principles of adult learning such as self pacing, reflective learning, and collaborative learning from peers. 1 It is necessary for the participants to note a number of advantages of online learning. Although there are only rare examples in the literature of online courses on communication skills for disaster professionals or students, 2 this study does add to the growing literature in disaster and in fields outside of disaster, 3-5 suggesting the effectiveness of Internet-based distance education. However, more rigid evaluations with control groups and a larger number of participants are required to establish which factors and participant characteristics are determinants of effective learning. Previous studies generally show that Internet-based instruction is at least as effective as conventional methods6-8 and in some cases superior.9-11 A recent meta-analysis of Web-based learning in disaster education, however, did acknowledge that studies are needed that better compare instructional methods rather than comparing instructional media although it still did not find this method superior to conventional methods.12 A carefully-designed, instructed, and evaluated online course may effect better learning outcomes than face to face instruction.13 Based on the limitations of research to date, it is clear that further work is needed to assess the impact and acceptance of small group online education, and the role of faculty or other moderators in online disaster education courses.9,14-16 The acceptance of this method in a broader, unselected student population will be of interest. Evidence suggests that most learners will ultimately be successful online learners.17

However, there was consistency of findings from the mixed-method approach used to evaluate this course. Governments should focus on their role as sponsors of basic scientific and technological research, bridging the digital divide, fostering public-private partnerships, managing international cooperation efforts, and establishing the regulatory and incentive components. All stakeholders must work collaboratively to grapple with the many standardization and infrastructure development issues and the transnational and global elearning aspects that must be addressed in a comprehensive manner. International aspects of e-learning services form a critical and urgent area still to be addressed by the World Trade Organization and regional trade blocks.

The public sector, the industry, and partnerships have the responsibility for assuming an active leadership role in educating the disaster community and in coordinating and 
encouraging the effective implementation of relevant applications. Disaster organizations must be provided with information about the opportunities as well as the risks of e-learning solutions. Technology-evaluation sources and results must be made available and disaster managers must be guided in the difficult process of specifying systems, procuring, acquiring, and contracting for ICT products and services. Knowledge repositories must be established in cooperation with the industry, centers for technology evaluation, academic research groups, and centers of excellence.

Organizational and human-resources development through awareness programs, education of disaster staff, continuous training, and career opportunities must be institutionalized from the inception of the developmental effort. Transference of technical expertise and the appropriation of knowledge by disaster personnel are necessary for the full participation of endusers in the development process and the best insurance for successful implementations. Success in the deployment of institutional e-learning applications depends on the existence of staff with the right mix of skills in all functions and levels. Recommended strategies include:

1. A structured human-resource development program defined with the goal of increasing awareness of e-learning opportunities and training disaster professionals to assume a leadership role and actively participate in all aspects of systems design and implementation.

2. The training strategy will take into account issues associated with the development, the organizational environment in which systems are expected to operate, and the specific circumstances of the local disaster system. The following guidelines for training should be implemented, such as identifying target groups based on functions and training needs; developing training programs to meet identified target groups' needs; and establishing a network of training focal points, taking into account the specific organization and circumstances of national characteristics and local disaster unit requirements and undertakings.

3. Target groups to be considered are those who originate, collect and supply data; operational decision makers; managers, planners, and policy makers; information systems managers; information technology and computing specialists; data analysts; and statisticians and researchers.

4. Each country will develop its own strategy for initial and continuing training in disaster -information systems, considering the overall development of disaster information systems and its particular educational, research, and market environment.

The internet will radically change medical education. The next decade may see the emergence of a new type of disaster school. It will not be made of bricks and mortar, but based mostly in the hard drives of computers, accessible by thousands of students all over the world. New investment trends are driving this efficient, cheap, and convenient way of delivering information. E-learning potentially offers huge benefits for users. It includes self 
paced courses, available anytime and anywhere, guaranteed consistency, personalized and relevant, easily updated, easy tracking and reporting, and reducing logistical costs (travel, space, materials). International recognition of training will also be assured since companies will demand international collaborations. This is because national systems will always be perceived as being of variable quality. U21 includes universities in Europe, China, North America, Australia, and New Zealand. Other universities, such as Oxford, are setting up their own international consortiums. It is a convenient medium for ongoing education, a necessity in the disaster field.19

There are other obstacles. Some estimates suggest that it takes 200 hours to produce one hour of online tuition, invoking the need for huge investment. Despite the current investor frenzy, online learning has not yet produced commercial success. The University College of Los Angeles school of dentistry spent $\$ 750000$ ( $£ 535000$ ) over five years developing an online course to train periodontists. It has been a commercial failure. 20 So it seems that the correct business model has yet to be found. But with such large potential revenues from electronic education, it is only a matter of time before the right solution makes e-learning a reality. Clearly e-learning will not wholly replace teacher led or hands on training. Online scenarios may be used to gain confidence and appropriate background knowledge before the hands on portion of learning, replacing time spent learning theory, with more time mastering the skill.19. Crucial supervised practice can then follow to gain essential on-site experience. Furthermore, certain areas lend themselves more easily to online teaching. Multimedia instruction is particularly well suited to help students.21

New models of disaster education will continue to emerge as the qualities and knowledge required by juniors is constantly reviewed. But there seems little doubt that electronic learning will be right at the centre of its future. However, this report demonstrated that the e-learning of disaster education was still primitive in countries. It should be the first priority to implement a sound e-learning environment to provide good disaster education information and education to promote the preparation of disaster response in the public in this country.

\section{References}

1. Whitman N, Schwenk TL. The Physician as teacher. Salt Lake City, UT: Whitman Associates; 1997.

2. Fleetwood J, Vaught W, Feldman D, Gracely E, Kassutto Z, Novack D. MedEthEx Online: a computer-based learning program in medical ethics and communication skills. Teach Learn Med 2000;12:96-104.

3. Ryan WJ. Online and in the classroom: the numbers and what they might mean. In: Community College Innovations Conference Boston, MA: League for Innovation in the Community College; 2002.

4. Thirunarayanan MO, Pérez-Prado A. Comparing Web-based and classroom-based learning: a quantitative study. Journal of Research on Technology in Education 2002;34:131-137. 
5. Johnson SD, Aragon S, Shaik N, Palma- Rivas N. Comparative analysis of online vs. face to face instruction. In: De Bra P, Leggett JJ, editors. Proceedings of WebNet 99: World Conference on the WWW and Internet Charlottesville, VA: Association for the Advancement of Computing in Education (AACE); 1999.

6. Mehta MP, Sinha P, Kanwar K, Inman A, Albanese M, Fahl W. Evaluation of Internetbasedoncologic teaching for medical students. J Cancer Educ 1998;13:197-202.

7. Hobbs GD, Moshinskie JF, Roden SK, Jarvis JL. A comparison of classroom and distance learning techniques for rural EMTI instruction. Prehosp Emerg Care 1998;2: 189-91.

8. Zucker DM, Asselin M. Migrating to the web: the transformation of a traditional RN to BS program. J Contin Educ Nurs 2003;34:86-9

9. Chan DH, Leclair K, Kaczorowski J. Problem- based small group learning via the Internetamongcommunityfamilyphysicians: a randomized controlled trial. MD Comput

10. Leong SL, Baldwin CD, Adelman AM. Integrating Web-based computer cases into a required clerkship: development and evaluation. Acad Med 2003;78:295-301

11. Radjenovic D, Wallace FL. Computerbased remote diabetes education for school personnel. Diabetes Technol Ther 2001;3:601-7

12. Chumley-Jones HS, Dobbie A, Alford CL. Web-based learning: sound educational method or hype? A review of the evaluation literature. Acad Med 2002;77(10 Suppl):S86-93

13. Lipman AJ, Sade RM, Glotzbach AL, Lancaster CJ, Marshall MF. The incremental value of Internetbased instruction as an adjunct to classroom instruction: a prospective randomized study. Acad Med 2001;76:1060-1064

14. Hay PJ, Katsikitis M. The 'expert' in problem-based and case-based learning: necessary or not. Med Educ 2001;35:22-6

15. Marshall JN, Stewart M, Ostbye T. Smallgroup CME using e-mail discussions. Can it work? Can Fam Physician 2001;47:557-63

16. Spallek H, Pilcher E, Lee JY, Schleyer T. Evaluation of web-based dental CE courses. J Dent Educ 2002;66:393-404

17. Harasim L, Hiltz SR, Teles L, Turoff M. Learning networks: a field guide to teaching and learning on-line. Cambridge, MA: The MIT Press; 1995.

18. Cohen JJ. Leading the Information Revolution. 1997. URL: http://www.academicmedicine.org/ accessed in Dec. 12, 2004.

19. Goettner P. Effective e-learning for healthcare. Health Management Technology 2000;21:63-4

20. Lessons of a virtual timetable. Economist 2001:1013

21. Grundman JA, Wigton RS, Nickol D. A controlled trial of an interactive, webbased virtual reality program for teaching physical diagnosis skills to medical students. Acad Med 2000;75:5479 